\title{
Implications of State and Local Policy on Community College Transfer in California
}

\author{
Dr. Lynn Ceresino Neault ${ }^{1} \&$ Dr. William E. Piland ${ }^{2}$ \\ ${ }^{1}$ Vice Chancellor, Student Services, San Diego Community College District, San Diego, CA, USA \\ ${ }^{2}$ Professor Emeritus, San Diego State University, San Diego, CA, USA \\ Correspondence: Dr. William E. Piland, Professor Emeritus, San Diego State University, San Diego, CA, USA. \\ E-mail: piland1@mail.sdsu.edu
}

Received: July 31, 2014

doi:10.5430/ijhe.v3n4p24
Accepted: August 25, $2014 \quad$ Online Published: September 1, 2014

URL: http://dx.doi.org/10.5430/ijhe.v3n4p24

\begin{abstract}
Lower division transfer preparation for the university has been the primary mission of community colleges since their inception creating an important pathway to baccalaureate degree attainment for many students who may not otherwise have the opportunity for higher education. Once considered fairly straightforward, the transfer pathway has become overly complex and difficult for students to navigate. The underlying issues with community college transfer are multifaceted and profound, and often the focus of much attention by public policy makers. This study explored the extent to which the complexity with transfer is rooted in flawed state and local policy coupled with insufficient capacity to meet the growing demand for postsecondary education at many public universities in California. Interviews with key players in higher education in the state, a focus group of community college professionals involved with transfer, observations of meetings where transfer was discussed and a review of state and local documents concerned with transfer comprised the methodology of this study. Results suggest that legislative interference in the transfer pathway, university elitism and selectivity, uneven placement of state resources, the confines of the state master plan for higher education and inadequate capacity at the state universities all contribute to damaging the transfer pathway.

This embedded case study examined the transfer pathway in one large region in southern California in the first decade of the 21 st century.The study investigated the implications of flawed public policy and insufficient capacity at some public universities on the development of local policy, and the unintended consequences for transfer students who are denied admission to transfer.Further, the study described how these policy decisions are hindering access and equity in the public postsecondary education system in the region under investigation. Amidst fluctuating economic conditions, the public higher education system in California has struggled to meet increasing enrollment demand. With the ongoing deterioration in state appropriations for higher education in California, the need for increased baccalaureate degree attainment to meet the future economic demands of the state is more critical than ever.
\end{abstract}

Keywords: Community college transfer, Transfer pathway, Capacity constraints, State and local transfer policies, Legislative interference, University elitism, Master plan for higher education, Uneven demand and distribution of resources, System structure

Lower division preparation for the university has been an important mission of community colleges since their inception(Eells, 1931).Over time the mission of community colleges changed to include associate degrees and certificates, along with economic and workforce development, basic skills and lifelong learning (California Community Colleges Board of Governors, 2006). Even today lower division transfer preparation remains at the core, creating an important pathway to baccalaureate degree attainment, particularly for the public higher education system in California.

California has always been a leader in the development of community colleges, consistently accounting for at least one-fourth of the community college enrollment in the nation. In the early decades of community colleges, the transfer function was thought to be relatively simple (Kintzer, 1996). It was considered to be a vertical path from high school to community college and then to the university. In the later part of the $20^{\text {th }}$ century, community college 
transfer in California became more complex as students and transfer advisors began to navigate through a maze of changing general education patterns, uncommon course numbering systems, limitations with course availability and inconsistent academic program preparation for different universities, even within the same system. Moreover, as economic conditions fluctuated, many of the public universities in the state struggled to meet increased student demand.

The viability of the transfer mission has undergone considerable scrutiny as policy makers look to transfer outcomes as a measure of institutional success. Lower than expected transfer rates have been the subject of much research and debate, and are considered by many policy makers to be the responsibility of the community colleges (Dougherty, 1992; Handel \& Williams, 2012). Some critics have contended that students who begin their studies in a community college are less likely to complete a baccalaureate degree (Dougherty \& Townsend 2006; Pascarella\&Terenzini, 1980).

\section{Background to the Problem}

The challenges students face navigating the transfer process are largely due to varying, and seemingly convoluted transfer requirements at the universities that often change at the last minute, leaving students discouraged and unprepared. These challenges in California were highlighted in a 2009 report by Moore and Shulock, which firmly stated, "the maze of requirements facing a California community college student designing an individual transfer plan is frustratingly difficult to navigate" (p. 5). Confounding the problem in California is the impaction policy employed by the California State University (CSU) where campuses can establish additional admission requirements at both the campus and program level to manage escalating demand. In their study, Moore and Shulock (2009a) noted the problems that have resulted from the CSU impaction policy positing, "just when they [students] think they have met the requirements for transfer to a particular program, those requirements are changed so that additional courses or grade point average are required" (p.6).

The concern with the transfer pipeline in California is evidenced by the number of statewide initiatives and resources that have been dedicated to improving transfer, most with disappointing results. Unfortunately, there has been very little focus on the inadequate capacity at many public universities to accommodate all of the potential demand. In a 2009 study, Moore and Shulock noted issues with insufficient capacity in the public university systems as demand for enrollment continued to surge in California, stating: "with the CCC [California Community Colleges] facing enrollment demand that far exceeds capacity and with UC (University of California) and CSU likely accepting fewer transfer students, a streamlined transfer process becomes more important than ever" (Moore \&Shulock. 2009b, p. 3). Nonetheless, there has been a paucity of empirical research assessing the impact of capacity constraints at the universities on the community college transfer function.

\section{The Problem}

The challenges with transfer in California have been exacerbated in the last decade as public higher education has faced increased demand, along with insufficient funding and inadequate capacity. Lack of sufficient space to accommodate eligible transfer students, as promised in the California Master Plan for Higher Education adopted in 1960, has resulted in more rigorous admissions standards at many of the public universities. The Master Plan, which became a model for states across the country, restructured the higher education system in California into three segments. The University of California system would become the major research universities in the state and offer doctoral and professional degrees. The California State University system would offer most of the upper-divisional baccalaureate education and some graduate programs. The community colleges would offer the first two years of undergraduate education and vocational educational programs.

Confounding the situation has been unpredictable and frequent changes to admission criteria by the universities. In some regions, changes to admission standards often have been made at the last minute because of uncertain economic conditions resulting in changes to the rules for many community college students mid-way through the process of preparing to transfer. This tactic has only added to the confusion with transfer. This study examined the viability of the transfer pathway to impacted campuses of the California State University system, with an emphasis on one campus of the CSU in Southern California.

\section{Research Questions}

This study examined the following tworesearch questions.

1. What are the factors that are impacting improving the effectiveness of the transfer pathway?

2. How are capacity constraints at public universities influencing the development and implementation of state 
andlocal policies that are impacting community college student transfer?

\section{Research Design}

The research design relied on several sources of data including: interviews with key local community college and university leaders who had been involved with transfer in the state throughout the first decade of the $21^{\text {st }}$ century when the transfer pathway has been volatile and, at times, contentious; key state level leaders from both the community college system office and the state university system who have been directly involved with transfer policy and issues; analysis of various documents from the community colleges and the universities pertaining to transfer including how the transfer pathway is communicated to students; examination of state policies concerning transfer matters that have been enacted in the last ten years; and finally, observations of regional and statewide meetings where transfer issues were discussed and efforts to implement new transfer policies were negotiated. The data gathered from these various sources were analyzed and triangulated to develop corroborating themes.

\subsection{The Local Setting}

While this study investigated difficulties with the transfer pathway at the state level, it also focused on one area of the state to demonstrate how statewide policies are implemented at the local level and the implications of that implementation. The public postsecondary education landscape in the region under investigation consists of eight community colleges, along with Central City University, Southern Research University and North Regional State University. The total undergraduate enrollment in the community colleges in the county has fluctuated over the past five years, averaging about 140,000 students each fall semester.Over the past five years, collectively the community colleges have transferred between 4,000 and 5,000 students annually. Two of the three public universities in this region of the state are quite large. In 2011-2012, Central City University enrolled almost 26,000 undergraduate students, Southern Research University's undergraduate enrollment was more than 22,000and the undergraduate enrollment at North Regional University was about 9,500 students.

\subsection{Interview Participants and Protocols}

This study utilized purposeful sampling of educational leaders who were the most knowledgeable about transfer admission, at the state level and in the region to ensure the most "information-rich cases" (Merriam, 1998, p. 62). The participants included: faculty leaders, deans/directors, vice presidents/vice chancellors, presidents/chancellors representing the community colleges and the universities both at the state level and in the region under investigation. In addition, the participants included a cross-section of leaders from academic and student affairs. Twenty-two people were interviewed.

Interview questions were designed to obtain the perceptions of local and state educational leaders about community college student transfer, including what they believed to be underlying the complexities and confusion with the transfer pathway. The questions for the interviews were pilot-tested to ensure that they yielded meaningful information. The interview questions were modified based upon the results from the pilot test.

The initial interview questions were fairly broad and conversational to establish a rapport, focusing on the participants' background and involvement with the transfer pathway. These questions were followed by a series of more narrowly focused questions that addressed: the participants' perception of the transfer pathway in the first decade of the $21^{\text {st }}$ century; perception of the relationship between the community colleges and the universities in the region; the participants' characterization of the community college transfer pathway in the past decade; what each participant believed to be at the core of the issues with transfer; perception of the effectiveness of statewide initiatives to improve transfer; and participants' understanding of, as well as reaction to, the implementation of the most recent statewide initiative to improve community college transfer, the Associate Degree for Transfer (SB 1440).All interviews were conducted during the 2011-2012 academic year.

The researchers also gathered information from a focus group comprised of the community college transfer center directors from six community colleges in this region. Similar data collection protocols were used for the focus group as with the one-on-one interviews. The questions that were used for the focus group were similar to some of the questions used for the interviews. In addition, there were questions that specifically focused on the challenges that transfer students face navigating the transfer pathway including: what the participants perceived to be at the core of the confusion with transfer; and the challenges participants face advising students about the transfer pathway. The focus group was conducted during the fall 2012 semester.

\subsection{Observation Incidents}

The observation phase of the study was conducted at statewide and regional meetings where transfer issues were 
discussed and negotiated. The participants in the meetings selected for observation comprised attendees representing both the community colleges and universities. Observational data were gathered from eight different meetings addressing both transfer policy matters and operational issues. Two different observations were conducted at meetings of the statewide transfer task force, comprised of faculty and administrative leaders from the California Community Colleges and California State University, both from local colleges, as well as representatives from the respective system offices. The state leaders of both the community college and state university systems had charged the transfer task forcewith implementing the most recent statewide policy intended to improve transfer (Associate Degree for Transfer SB 1440), the new guaranteed associate degrees for transfer to the California State University.

Observational data were gathered from three regional meetings, addressing regional transfer matters and local policy, with community college transfer center directors and other university and community college leaders who are responsible for transfer at their respective institutions. In addition, observational data were gathered from two meetings of a regional coordinating body for higher education policy matters comprised of presidents, chancellors and representatives from the public community colleges and universities in the region when transfer was on the agenda. Finally, data were gathered from an observation of one statewide meeting of leaders representing the various constituency groups of the community colleges focused on the implementation of SB 1440.All of these meetings occurred during the 2011-12 academic year.

To facilitate accurate collection of observational data the researchers employed the following techniques depending upon the size of the meeting and familiarity with the participants: created a seating chart with the names and affiliation of each participant at the onset of each meeting; described each participant in detail for future reference as the dialog was reconstructed; and recorded detailed notes of the discussion and interaction including body language, facial expressions, and voice intonation, as relevant. The data gathered from the meeting observations were triangulated with the interview and focus group data, along with data gathered from document analyses, to corroborate and substantiate the description of the phenomenon under investigation.

\subsection{Document Review}

The researchers examined various institutional documents that included or referenced transfer information, including college catalogs, class schedules, transfer bulletins and websites to determine how clearly the community colleges and public universities convey information to students about the transfer pathway in the region. Specificity, simplicity and clarity of the information were examined to answer several questions. Does the information explain the transfer pathway in broad terms or detail? Is the material comprehensive enough for prospective transfer students to navigate the process on their own or does it require further explanation by an academic counselor? Does the information demonstrate a strong transfer culture at the institution? A Document Analyzer was used to analyze the variouslocal institution publications.

The researchers also examined statewide and local policies related to transfer in the first decade of the $21^{\text {st }}$ century to identify the formal state rules in use, as well as the local iterations of the rules. For purposes of this study, a local policy is a rule or requirement as noted in a college or university catalog. In addition, memoranda as well as state legislation and institutional policies were reviewed to determine the specific intent of each. The same Document Analyzer was used for these external documents. The Document Analyzer was constructed to include columns and rows to categorize and evaluate the information with a rubric for assessing the pertinent components of the documents.

\section{Data Analysis}

The researchers for this study analyzed the data throughout the data gathering process by following Creswell's (2009) recommended approach for data analysis. The researchers organized the data by transcribing interview and focus group recordings, the notes from meeting observations and completed the Document Analyzer. They then conducted a broad overview of the data to develop a general understanding of what the data revealed and identified major themes and subthemes. Finally, they assigned codes to the interview and focus group data. Each group of data was assigned a label that broadly described the topic. The final step of the coding process was a more focused review of the codes to further organize segments of the data that were similar. Through this process, the data were synthesized until themes emerged from the data.

The final step in the analysis was to triangulate the multiple sources of qualitative data to identify common themes and subthemes, develop conclusions, and write a detailed analysis. Themes from these multiple sources that reinforced each other were integrated to address the two research questions. 


\section{Findings of the Study}

There is no transfer pathway, it is an ever shifting road...you climb a hill and then you find other hills you knew nothing about...then the road dips down, then it rises, there is no map, no sign posts, you can't tell how far away you are from the goal.

Community College Administrator

\subsection{Research Question 1: Factors Impacting Improving the Effectiveness of Student Transfer}

The results of this study demonstrate that there are four primary factors believed to be at the crux of the challenges with improving the transfer pathway: the governance structure of the three segments of higher education in California; the complex state political arena that influences the development of public policy pertaining to higher education and student transfer; the elitism of the senior institutions; and, insufficient capacity in the public universities.

\subsubsection{Governance Structure}

The broad framework for higher education in California was established by the California Master Plan for Higher Education in 1960. Principally, the plan promises access to postsecondary education for everyone, and delineates a specific mission for each of the three segments of public higher education, as mentioned earlier.

Participants in this study noted that upholding the principles and promise of the Master Plan for Higher Education is contributing to the struggles with ensuring an effective transfer pathway for students. Reflecting on the troubled transfer route to the baccalaureate degree, one long-time community college leader noted: “...maybe it is time to seriously reconsider the California Master Plan for Higher Education and have one authority for education in the state..." The constraints of the Master Plan were echoed by a local university official who characterized the plan as "ill-conceived" and commented on the fact that many of the basic tenets of the plan are largely outdated and no longer sustainable, opining that: "...no part of our life is guided by a 50 year old blueprint."

When participants were asked what they would do to improve transfer, most presented bold solutions, many of which were in direct conflict with the principles establish by the Master Plan. Examples of these proposed solutions included: changing the mission of the three segments of postsecondary education, such that the community colleges would be the primary provider of lower division education; eliminating basic skills instruction in the community colleges and "getting students prepared in K-12;" narrowing the competing missions of the community colleges; and, establishing admission requirements for the community colleges. One community college leader captured the opinions of most respondents regarding what it would take to improve the effectiveness of the transfer pathway: "I think we need to have some radical change."

\subsubsection{State Political Arena}

A second dominant factor identified in the data that was determined to be contributing to the ongoing complexities of the transfer pathway in the region was the state political arena. One influential participant in the study reflected on the fact that development and implementation of educational policy is such a challenge in California because of the size and structure of the state. To illustrate the point, the participant recalled a statement made several years ago by a public official that "the problem is that California is an abstract concept, there is no such thing in reality, and those trying to promote things for California fail."

Interview participants were resigned to the reality of what was frequently characterized as interference by elected officials, and went into depth about the consequences of the legislative stranglehold on community colleges. Reflecting on the assumptions underlying the development of statewide initiatives to streamline transfer, one state level community college leader explained: "you have politicians which are part of our nemesis, with legislators being party to what we do..." Another state level leader, involved with the development of state policy stated:

A lot of these [initiatives] are just politics, coming down fast and furious - it sounds good so let's do it —and then the field says, wait a minute, we can't do that, slow down, but a lot of times the train is moving too quickly and we can't stop it, and then we are expected to implement something when there are just massive issues...so again, it is more confusing and complex.

Information gathered from meeting observations also reflected a strong political influence on community colleges. At two statewide meetings on the implementation of the most recent initiative, SB1440community college representatives at the meetings made veiled threats about involving the author of the original bill to make sure that the universities would follow the intent of the bill. This bill, titled the Student Transfer Achievement Reform Act, intended to streamline and improve transfer in California. The bill specifies that community colleges and the California 
State University (CSU) system collaborate to structure associate degrees for guaranteed transfer to a CSU campus. The bill also specifies that for these degrees, a community college cannot require students to take any additional course requirements for the associate degree for a total of 60 units/credits. After transfer, the CSU is prohibited from requiring any more than 60 upper division units to earn a baccalaureate degree.Further, at a different statewide meeting of community college leaders, when reporting on the progress of implementing SB 1440, statements were made about the universities having to cooperate or there would be new legislation to force them into a more cooperative stance.

\subsubsection{Institutional Elitism}

A third major factor believed to be impeding improvement of the transfer pathway in the region is that the universities view the community colleges as less than, or not "real" institutions of higher education. In response to what is at the core of the challenges with the transfer pathway in the region, one community college leader suggested:

I think it comes down to budget and the universities' interest in being exclusive and elite. By virtue of trying to become elite institutions, they make policy decisions that impact transfer at the local level...as they have to decrease enrollment, they are going to open the door to those students that will be more likely to succeed.

One study participant expressed disbelief that admission requirements are increasing due to the need for better preparation of transfer students reflecting on the history of the performance of transfer students at the universities:

The four-years tell us our students do well when they get to the university, and they were telling us that when the GPA (grade point average) to get in was a 2.0 , a 2.5, a 2.8, a 3.0 and a $3.5 \ldots$ our students have always done well...it is not as if the new criteria are sending a better quality student than in the past.

When asked if the decision to substantially increase the GPA requirement was based upon poor preparation of transfer students who transferred to the university, the university official responded: "clearly preparation was not the issue..."

Reflecting on the future viability of community college transfer agreements one university official expressed concern about guaranteeing admission to students with potentially lower grade point averages, again implying that the university views transfer students with a $3.0 \mathrm{GPA}$, on a 4-point scale, as marginal:

We cannot turn away reallyprepared students [emphasis added]...it is really tough at times. Should we beso tied to a [transfer] guarantee that we are going to sacrifice quality and equity? We are turning away excellent students and admitting students at the $3.0[\mathrm{GPA}]$ level.

One explanation for the perception of selectivity on the part of the universities in the region in relation to the challenges with transfer was provided by a local university official who framed what he believed to be conflicting values between the two segments: "It is different value sets...the quality and academic preparation is important to us, so we are always trying to raise the bar, which is counter to the community college notion that everyone should get a try."

Nonetheless, community college participants viewed the situation quite differently and were emphatic that the bar is raised and lowered as the university needs students, not to improve the preparation levels of transfer students as captured in the following statement from one local community college leader: "When they need to grow FTE (full-time equivalent students) universities open the spring [semester] up, they lower the GPA...then they are impacted, then no longer impacted, they will do whatever they need to get our students when they need them..."

Evidence of the superiority of the universities also was found in the data from the meeting observations. For example, at one statewide meeting of university and community college officials, both faculty and administrators, that focused on the implementation of the new transfer degrees, three of the university representatives were noticeably disengaged in the meeting. While the meeting was in session, two university participants never looked up from their laptop computers, and typed non-stop throughout the discussion clearly focused on something other than the meeting. Moreover, all three of the participants did not have any comments or interaction with other meeting participants during the three-hour discussion. A third university representative read messages on his Personal Digital Assistant (PDA) throughout the duration of the meeting. Other behaviors at the meeting demonstrating elitism were that university officials all sat on the same side of the table, and the majority did not interact with community college representative during breaks or lunch.

\subsection{Research Question 2: Impact of Capacity Constraints on Policies Affecting Student Transfer}

We are locked into a hopeless embrace. We can't separate ourselves from the [universities]; they can't legally separate themselves from us, though a number of their campuses act as if they could. We just get into 
these round and round discussions trying to address the problem but never get anywhere because the problem is: too few seats and the ever changing rules about how to limit students' access to those seats — rising GPAs for majors, earlier deadlines, and supplemental applications.

Community College Administrator

Following are the major themes and subthemes that emerged in response to research question 2.

\subsubsection{Lack of Sufficient Capacity at Many Public Universities}

The major theme that emerged from the data is that inadequate capacity at the three public universities in the region, all of which are impacted, has created an unstable and overly complex transfer pipeline. Several subthemes also emerged within the broad context of high demand and insufficient supply which aredepicted in Table 1 and discussed in the following section.

Table 1. Primary and Secondary Themes Concerning Capacity Constraints

\begin{tabular}{ll}
\hline Primary Theme & Secondary Themes \\
\hline Lack of Sufficient Capacity at Many Public & Local Policy Development and Unstable Transfer \\
Universities & Admission Requirements \\
& Local Policy Development as an Enrollment Management \\
& Strategy to Address Capacity Limitations \\
& Impact of Capacity Constraints and the Viability of the \\
& Community College Transfer Pathway \\
\hline
\end{tabular}

\subsubsection{Local policy development and unstable transfer admission requirements}

Unpredictable and rapidly changing admission requirements, often announced at the last minute, were a strong secondary theme that emerged in the data. Participants agreed that the rapid changes in policy were at the root of much of the confusion with the transfer process. Some participants explained that these changes in policy often were made mid-way through a student's transfer preparation, describing the situation as an endless climb for students as captured in the following statement from one community college leader:

I think the university is being forced into a tighter rationing of available seats which is dependent upon state funding. Because of the rationing they make up new rules, they set new standards because of what is now the typical late development of the state budget the university does not know how many seats they will be able to offer students, and so they delay their decisions and invent new rules and/or deadlines to control access.

Several of the focus group participants agreed that it is disheartening that policies change so frequently that the professionals who students depend upon to help them navigate the transfer pathway are severely challenged keeping up with all the changes to effectively advise students. The following comment encapsulates the discussion: "[Transfer] is not effective due to inconsistent and changing rules so suddenly, [which] makes it difficult to advise students. A lot of times the rules change internally and we are never told why students were admitted or denied."

The impact of the erratic, last minute changes to admission policies for transfer was found in the data from the meeting observations. In one meeting of local university representatives and transfer advising professionals that focused on upcoming changes in transfer policy, the group spent over an hour discussing the changes in great detail. Community college representatives expressed considerable frustration with the change as evidenced by body language and repeated clarifying questions. There also were a number of "sidebar" conversations between community college representatives while the university presenter was speaking. Finally, the complexity of all of the rules was evidenced in the meeting observation by the fact that there were eight representatives from one university who attended the meeting to answer questions about program requirements and various admissions rules.

Evidence of the concern over erratic and last minute changes to admission requirements in the region under investigation also was found in the document analysis of state policy. For example, in response to an outcry from the local community, a legislator representing the region introduced a bill-that later became law (AB 2040, Chapter 262, September 23, 2010) - that established specific criteria that must be met prior to any change to admission requirements for a campus of the CSU affecting the local service area. The new law, informally referred to as the 
transparency bill, requires a campus of the CSU to comply with a list of criteria before making a proposed change in admission requirements that affects the local service area.

6.2.4 Local policy development as an enrollment management strategy to address capacity limitations

Another strong secondary theme that emerged from the data, related to the impact of insufficient capacity on the development of local policies for transfer, is the belief that local transfer policy development is commonly used as an enrollment management strategy to constrict or expand the number of eligible applicants, however eligible is defined. Practices that were frequently mentioned were: increased amounts of required preparation for the major; elevated and often fluctuating minimum grade point averages for impacted majors; restrictions on where community college coursework was completed; and the use of a supplemental admission application for transfer students.

Participants frequently expressed frustration with transfer policies being used as an enrollment management strategy as illustrated in the comment from one state level community college leader, "I think we use transfer preparation for enrollment management purposes...so we are overly complicating and saying it is transfer preparation, but it is really a way to control the number of applicants..." Further, many study participants were not convinced that the evolution of more stringent transfer admission requirements through the years was prompted by the need to ensure that transfer students are better prepared as purported by university officials. Rather, they argued that the rising standards are solely a result of managing supply and demand.

The data gathered from the meeting observations corroborates other findings that suggest that changes in admission policies are a mechanism used by the universities to control enrollment. One clear example was uncovered in a discussion at one meeting of community college leaders about the sudden opening of the spring 2011 transfer admission cycle at Central City University. The irony of opening up spring admission for transfer students was that significant numbers of transfer applicants were denied admission in the fall of the same academic year. Further troubling to the community college leaders at the meeting was that the stringent admission requirements imposed upon students who applied in the fall were completely abandoned for spring since the university needed to meet their enhanced enrollment targets.

6.2.5 Impact of capacity constraints and the viability of the community college transfer pathway

The viability of the community college transfer pathway, emanating from capacity constraints and the resulting changes to state and local policies pertaining to transfer, was evident in the data. Many participants shared the perspective that the transfer pathway is no longer reliable as illustrated by the following response from one study participant "No, it [transfer] is no longer a given. It used to probably be a given a few years back, but not anymore. Students are now hoping and praying that they will get in to their local universities."

Feedback from focus group participants also reflected an overall lack of confidence in the reliability of the transfer route to the baccalaureate degree in relation to advising students. The most dominant factor reported to be destabilizing transfer was the last minute changes to the transfer rules, making it nearly impossible to provide reliable information to students. The group provided concrete examples of how the information they give students today, may not be accurate tomorrow. The following comment illustrated the depth of the problem: "when I am advising students, I tell them this is what I know now; it does not mean it will be accurate next month."

\section{Conclusions}

Student transfer from the community colleges to the public universities in California has become unstable and difficult for students and educators to maneuver. The findings in this study showed that the transfer pathway has become overly complex and highly volatile due to several multifaceted factors. These factors comprise a hierarchy of constraints to a simple and effective student transfer process, each with arguably varying influences on what has been described as the decline of the transfer mission. The hierarchy of constraints and the resulting impacts on students and the state are depicted in Figure 1. This hierarchical structure forms a framework for the conclusions in this study. 
Impacts

\section{Constraints}

\subsection{Constraints}

Figure 1. The transfer pathway: constraints and their deleterious impacts

The data show that there are multiplicities of constraints to an effective and simple transfer pathway.

7.1.1 System structure and the confines of the state Master Plan for Higher Education

The California Master Plan for Higher Education has guided public postsecondary education in the state for more than half a century. However, the structure of the public higher education system in California as envisioned by the Master Plan is a barrier to improving the transfer pathway at this time. Although the structure allows the three segments of public higher education a means for "accommodating enrollment demand through an integrated system of differentiated public and private institutions" (Taylor, 2010, p. 5), critics contend that the Master Plan "is a major barrier to addressing statewide higher education issues" (Richardson \& Martinez, 2009, p. 83). Further, Richardson and Martinez (2009) explained that critics viewed the plan as "a significant challenge - because of the degree of insulation it provides against change" (p. 82).

Successful student transfer from the community college to the university is central to the promise of educational opportunity for everyone since it provides students, who may not otherwise be eligible or have the financial means, a pathway to the baccalaureate degree. However, through the years, there have been significant challenges with the system structure which largely relies on coordination and collaboration between and among the three segments of higher education to meet the intent of the Master Plan. These challenges emanate from the reality that public higher education in California, while systems on paper, do not actually function like systems.

7.1.2 Inadequate university capacity and the state's divestment in public higher education

The state's ongoing divestment in higher education is taking a toll on the transfer pathway. Insufficient capacity at the public universities in the region, due in large part to unstable state funding for public higher education, is driving transfer admission policies that are inconsistent and unpredictable, creating a transfer pathway that resembles an 
ever-shifting road that is difficult for students to navigate. It is clear that lack of adequate capacity at the public universities in the region has created a dire situation that must be addressed, not only for the economic health of the region, but for the state.

\subsubsection{Uneven demand and the placement of state resources}

A significant impediment to meeting growing demand for public education in some regions of the state is that the placement of state resources for higher education is not commensurate with enrollment demand. In an analysis of public policy in higher education, Richardson and Martinez (2009) highlighted that public universities have been built in areas of the state to respond to political pressures from local communities when the demand was not there.

An illustration of the unevenness in demand and allocation of state resources can be found in the current impaction status of the various campuses of the California State University system. The universities use impactionpolicies to control enrollment.Some universities need students to meet their budgeted enrollment levels, whereas others have more student demand than they can accommodate, and are looking for ways to limit the pool of eligible applicants. Therefore, students at the community colleges trying to prepare to transfer face a maze of requirements and rules for different universities even within the same system. The net result is a transfer pathway that is convoluted and unmanageable for students.

\subsubsection{University elitism and selectivity}

As the public universities in the region continue to have more demand for enrollment than they can accommodate, the universities are raising their admission standards and becoming more selective, creating an impression of elitism and seemingly an overall lack of interest in community college transfer students. These practices and attitudes are contributing to the notion that community colleges are less thanacademic institutions, and thus transfer students are not good enough, a stigma that has existed since the early years of community college development. Yet, there is no empirical evidence that higher admission requirements result in better prepared students (Townsend \& Wilson, 2006). Nonetheless, the universities repeatedly communicate the need for more stringent requirements and university selectivity as justification for changes in the transfer pathway, conveying to the community colleges a message that many transfer students are not good enough for the university.

7.1.5 Legislative interference in the transfer pathway and disconnect between intent of legislation and implementation

State policy makers repeatedly muddle in the transfer process with top-down, one-size fits all solutions to improve transfer that are ignored or implemented differently throughout the state since the intent of legislation is often at odds with the realities of implementation.Unfortunately researchers and educational leaders have concluded that most of these initiatives have fallen short of anticipated results (California Postsecondary Education Commission, 2002).

Ongoing lofty endeavors by public policymakers to improve transfer through legislative initiatives that impose statewide consistency in educational systems that are not consistent themselves, are resulting in even more layers of transfer admission rules that are confusing. The most recent statewide initiative to improve transfer, SB 1440, is an example of the chaotic implementation of a "cookie-cutter" solution in a system that was described by one educational leader in the study as a "league of nations." Arguably intended to be regionally focused based upon the language in the bill, the new transfer guarantee program has been designed as a statewide approach that is incompatible with local autonomy and faculty control over the curriculum at some institutions.

\subsection{Impacts}

The results of this study demonstrate that the many constraints to creating a transfer pathway in California that is simple and straightforward for students to navigate are having a deleterious impact on students.

7.2.1 The unstable transfer pathway and abrogation of the transfer mission

Imposing transfer admission requirements to manage enrollment demand, under the cloak of impaction, has created an unstable transfer pipeline.University transfer admission requirements change frequentlywhich has created a high level of volatility with transfer.

Interpreting transfer requirements that are a moving target makes it very difficult to accurately advise students, which is prompting a sense of lack of credibility on the part of the community colleges. Transfer has become so complex due to the many layers of rules and admission requirements that can change suddenly, that most students cannot navigate transfer on their own. Transfer professionals can no longer confidently advise students on the proper transfer preparation since the requirements can change at any time. Along the way, mistakes in preparation for transfer happen and students are denied admission, often not knowing the specific reason for denial, and are left to 
their own devices to figure out how to remedy these vaguely defined deficiencies. In the final analysis, the volatility of transfer in the region has made selection of the transfer route to the baccalaureate degree a risky choice for students.

7.2.2 Students remain in community college taking excess units or stop out altogether;students defeated in their quest to complete a baccalaureate degree

Students who are denied transfer admission to their local public university largely remain in community college accumulating units they may not need, to improve their GPA to be more competitive in the admission process, or to prepare for a less competitive major - and ultimately continue to reapply to transfer - and another large group of those students not admitted to the university stop going to college altogether. Students who stop attending are taking time off from school, are working, or are simply defeated in their quest to complete a baccalaureate degree (Neault, 2012).

The state policy implications of transfer-prepared students remaining in community college in a holding pattern, waiting to reapply in the future, are significant, particularly at a time of deliberate down-sizing of community colleges as state appropriations diminish. Not only are these students taking up seats that are needed for other students preparing for degrees, certificates and transfer, this behavior pattern is contributing to the impression that the community colleges have poor student outcomes, and that transfer students complete too many units at the community college. Notwithstanding, the consequences of university impaction have the potential to disenfranchise large numbers of individuals, especially low income and students of color who disproportionately begin their postsecondary education at community colleges, and who may not have other educational options to complete a baccalaureate degree.

\subsubsection{Loss of an educated citizenry for California: a case for regionalization}

As enrollment demand has soared, various public universities in the state have struggled to meet the need given finite space. Of even greater concern is the fact that the demand for enrollment in the public universities in the state is uneven, ranging from fully impacted universities to campuses that need enrollment, and therefore accept students who meet the state minimum transfer requirements.

The unevenness in demand, and consequent disparate admissions standards, makes a strong case for regionally focused efforts to improve transfer, since many students are not portable to other areas of the state. Through the years the universities of the California State University system have been largely regionally focused as evidenced by local outreach efforts and a commitment to admission priority for local students including local transfer agreements.

Regional transfer initiatives, instead of a statewide "cookie-cutter" approach, are most desirable to bring community college transfer back into the normal progression of students moving unencumbered through their postsecondary careers. Of course, regionalization may not happen without some statewide direction or incentives. Therefore the following proposed solutions are directed to various entities at the state and local levels.

\section{Statewide Solutions - CSU Impaction and Enrollment Management}

1. The California State University (CSU) should standardize impaction admission requirements across all impacted campuses to minimize variances and simplify transfer requirements. One approach would be to establish simple classification levels of impaction, and identify standardized transfer admission criteria based upon each level, including impacted academic programs.

2. The universities should discontinue the use of transfer admission requirements to manage their enrollment which has resulted in an unreliable and tenuous transfer process. This action will help to stabilize the transfer pathway for students and facilitate strong university-community college relationships.

Statewide Solutions - System Improvements

3. The California State University and California Community College systems must support the original mission of the California State University as articulated in the Master Plan for Education, and place primary emphasis on serving their local communities. Acknowledging that the transfer pipeline between the community colleges and CSU is largely regional would allow institutions to formally focus efforts to simplify the transfer pipeline at the regional level, building upon existing articulation agreements and collaborative relationships, many of which have existed for decades.

4. The Legislature should reexamine the viability of the 50-year old Master Plan for Higher Education given the decline in state resources for public postsecondary education and the economic realities of California. The state should determine if it can sustain a plan that promises educational opportunity for all residents of the state, when in 
reality it does not have the resources to support the promise.

5. The Legislature should discontinue employing broad-brush, top-down, legislated directives as a mechanism to improve transfer. Instead, the Legislature should recognize that the higher education systems in California do not function as systems, and are comprised of highly autonomous institutions and faculties who have authority for the curriculum and programs.

6. The California State University should reconsider the proportion of upper division and lower division students at highly impacted campuses. Decreasing the proportion of freshmen would allow the universities to admit more transfer students who have already passed critical academic threshold points, and who have successfully completed the first two years of preparation for a baccalaureate degree.

Statewide Solutions - Postsecondary Education Resources

7. The CSU and UC should reallocate resources to meet the higher enrollment demands in some regions in the state. This would allow the universities to accommodate more transfer students in the areas where the demand exists and stabilize transfer.

Local Solutions - Empowering Students Through Information

8. The public universities on a regional basis should work with community college transfer center directors and other transfer professionals to develop consistent and simple transfer information for students considering transferring to local universities. The information in these materials including web pages, catalogs, schedules and other printed and digital material should reflect each university's transfer policies in a consistent format for students and the professionals who advise them.

9. Universities should inform transfer students who are denied admission of the specific reasons for denial. This action would allow students to know exactly what they need to do to remediate deficiencies and minimize the propensity for students to accumulate excess units at the community college, which is a waste of state resources.

Local Solutions - Commitment to Regional Access

10. Presidents/Chancellors of universities, along with their community college counterparts in regions with highly impacted universities should convene a region-wide task force comprised of senior-level leaders to develop a long-term strategic plan for higher education in each region of the state. The plan should focus on the critical role and structure of the transfer pathway given diminishing resources, extraordinary demand, and finite space.

11. The leaders of public universities should formalize a commitment to providing admission priority to all eligible local community college transfer students. The universities should embrace local transfer students who have consistently performed as well, if not better than freshmen students after transfer to the university, and acknowledge the value of an educated local community.

\section{References}

California Community Colleges Board of Governors. (2006). California community colleges system strategic plan.Sacramento, CA:California Community Colleges Board of Governors.

California Postsecondary Education Commission. (2002). Student transfer in California postsecondary education. Retrieved from http://www.cpec.ca.gov/completereports/2002reports/02-03.pdf, September 21, 2012

Creswell, J. W. (2009). Reserach Design. Thousand Oaks, CA: SAGE.

Eells, W. C. (1931). The junior college. Boston, MA: Houghon Mifflin Company.

Dougherty, K. (1992). Community colleges and baccalaureate attainment. Journal of Higher Education, 62(2), 188-214. http://dx.doi.org/10.2307/1982159

Dougherty, K. J., \& Townsend, B. K. (2006). Community college mission: A theoretical and historical perspective. New Directions for Community Colleges, 136, 5-13. http://dx.doi.org/10.1002/cc.254

Kintzer, F. C. (1996). A historical and futuristic perspective of articulation and transfer in the United States. New Directions for Community Colleges, 24(4),3-13. http://dx.doi.org/10.1002/cc.36819969603

Handel, S. J., \& Williams, R. A. (2012). The promise of the transfer pathway.Retrieved from http://advocacy.collegeboard.org/publications on January 11, 2012

Merriam, S. B. (1998). Qualitative research and case study applications in education. San Francisco, CA: Jossey-Bass. 
Moore, C., \& Shulock, N. (2009a). The grades are in-2008: Is California higher education measuring up? Sacramento, CA: Institute for Higher Education Leadership \& Policy.

Moore, C., \& Shulock, N. (2009b). Student progress toward degree completion: Lessons learned from the research literature. Sacramento, CA: Institute for Higher Education Leadership \& Policy.

Neault, L. (2012). Implications of State and Local Policy on Community College Transfer in California: A Regional Case Study. (Unpublished doctoral dissertation). San Diego State University, San Diego, CA.

Pascarella, E. T., \& Terenzini, P. T. (1980). Predicting freshman persistence and voluntary dropout decisions from a theoretical model. The Journal of Higher Education, 51(1), 60-75. http://dx.doi.org/10.2307/1981125

Richardson, R., \& Martinez, M. (2009). Policy and performance in American higher education. Baltimore, MD: Johns Hopkins University Press.

Taylor, M. (2010). The Master Plan at 50: Greater than the sum of its parts. Sacramento, CA: Legislative Analyst's Office.

Townsend, B. K., \& Wilson, K. B. (2006). The transfer mission: Tried and true, but troubled? New Directions for Community Colleges, 136, 33-41. http://dx.doi.org/10.1002/cc.257 